\title{
Hot and Cold IPO Markets: Identification Using a Regime Switching Model*
}

\author{
Tim Brailsford \\ Australian National University, Australia \\ Richard Heaney \\ Australian National University, Australia \\ John Powell \\ University of Otago, New Zealand \\ Jing Shi \\ Australian National University, Australia
}

The market for unseasoned equity has the unusual and distinguishing feature of periods of concentrated activity in terms of both volume and underpricing. This paper formally documents the existence of such periods using a regime-switching model that dates transitions between hot and cold states. A number of hot periods are identified over a 20-year period using a variety of IPO activity measures that capture different aspects of new issue volume, proceeds and underpricing. The study further documents a leading relationship between underpricing and IPO volume of up to six months. This relationship supports the contention that the decision to issue is a function of current underpricing. Various reasons are hypothesised for this result and the paper finds supportive evidence through a VAR analysis that reveals the influence of stock market and business conditions. The results have implications for the information contained in current market conditions and the role of issuers, underwriters and investors (JEL G12, G14, G32).

Keywords: hot issues, IPOs, regime-switching, stock market, unseasoned issues.

\footnotetext{
*The authors thank Liliana Gonzalez, Vince Hooper, Mohammad Tahir, two anonymous referees and the editor for their helpful comments.

(Multinational Finance Journal, 2000, vol. 4, no. 1\&2, pp. 35-68)

(C) Multinational Finance Society, a nonprofit corporation. All rights reserved.

DOI: $10.17578 / 4-1 / 2-3$
} 


\section{Introduction}

An important distinguishing feature of the market for initial public offerings (IPOs) is the tendency of the market to undergo periods of concentrated activity whereby the number of new issues coming to the market and the extent of underpricing (of the offer price relative to the initial trading price), both appear to substantially increase. These "hot issue" periods attract enormous investor interest and media attention because of their perceived potential for short term trading profits. But little attention has been directed towards formally identifying and examining the cyclical nature of these so-called hot and cold IPO markets, with the literature instead focusing on cross-sectional explanations of IPO underpricing per se.

This paper focuses on hot and cold IPO market cycles, and examines four monthly measures of IPO activity (volume, average underpricing, gross proceeds, and total underpricing) over the period 1976 to 1998 in order to provide a multi-dimensional characterization and identification of hot and cold IPO markets.

Objective dating and characterization of hot and cold markets can be important for the development and empirical testing of models of IPO cycles. Moreover, institutional and retail investors are interested in IPO return behavior during different stages of the cycle. For instance, financial managers need to know how long favorable cyclical conditions for new issues persist because of the relatively long lead time required to undertake an unseasoned issue. Characteristics of IPO cycles should also be of interest to regulators if they impinge on the efficiency and operation of capital markets.

The paper makes three contributions. First, it identifies in a quantitative manner hot and cold periods in the IPO market. While there is general acceptance in the literature that such periods exist, there have previously not been formal attempts to quantify these periodic episodes. Second, using a regime-switching model the paper provides an objective determination of the dates of hot issue periods over the last 20 years. Again this represents the first attempt in the literature to do so. Third, the paper examines relationships between IPO activity variables and other factors and finds significant results that reveal an association between IPO market activity and economic conditions.

More specifically, the paper applies Markov regime-switching to IPO 
data, and provides a multi-dimensional characterization of IPO cycles in terms of active versus inactive market volume, hot versus cold underpricing, and leading versus lagging market features. This latter characterization is possible through a vector autoregression analysis of leads from underpricing to IPO volume that indicates how long each state of the cycle is likely to persist. Inter-relationships amongst IPO underpricing and activity series indicate that underpricing leads the number of IPO issues by up to six months, thus indicating significant activity momentum over short time intervals. This evidence provides new insights to researchers seeking explanations of IPO market cycles and to market participants who are either seeking to bring new issues to the market or looking to invest in IPOs.

The organization of the paper is as follows. In section 2, the prior evidence is reviewed. The research method is described in section 3 while section 4 documents the characteristics of the data. Section 5 discusses the construction of the measures of IPO activity. The results are presented and analyzed in sections 6 and 7 . The paper is concluded in section 8 .

\section{Prior Evidence}

The IPO market is highly significant. Almost 14,000 IPOs were issued in the USA during the period 1960 to 1999 , representing an average of around 29 IPOs per month. ${ }^{1}$ Over the period 1990-99, $\$ 269$ billion was raised through the IPO market.

Prior studies have indicated that the level of IPO activity displays considerable variability, with concentrated periods of activity being apparent (eg. Helwege and Liang 1996, James and Kieschnick 1997). Ibbotson and Jaffe (1975) first documented that the degree of IPO underpricing is cyclical, with monthly underpricing observed at the beginning and end of the 1960s (1959-1961 and 1968-1969) of around 80-100\% (after adjusting for the market return) compared to an average of $12.6 \%$ over their sample period of 1960-70. Interestingly, they found that periods of extreme underpricing generally led a heavy volume of

1. Figures are constructed from various sources including Ibbotson et al. 1994, Securities Data Corporation and Wall Street Journal reports. 
new issues, and used the popular press term "hot issue" market to describe this phenomenon. Ritter (1984), who documented a further hot issue market in 1980, characterized hot issue markets by an unusually high volume of new offerings, severe underpricing, and frequent oversubscription of offerings. Ibbotson et al. (1994) confirmed the previously documented hot markets of the 1960s and 1980 and also observed the existence of hot issue markets in the mid-1980s and at the beginning of the 1990s. Hot issue IPO markets have also been documented in other markets, including the UK and South Korea in the late 1980s, and Germany during 1982-1983 and 1985-1986 (Ritter 1998).

Discussion of the time series properties of IPO cycles is limited. Ibbotson and Jaffe (1975) documented a high degree of autocorrelation in monthly underpricing which generally lasted for around 11 months. Ibbotson et al. (1994) have described the level of underpricing and IPO volume in terms of persistent processes where current period values are a good predictor of next period values. They observed that the firstorder autocorrelation coefficients of monthly average initial returns and IPO volume are .66 and .89 , respectively.

The level of IPO activity has traditionally been viewed in terms of two measures - a volume measure such as the number of new issues (Ritter 1984) and a pricing measure such as the average level of underpricing (Ibbotson and Jaffe 1975, Ritter 1984). Studies have generally used graphical and autocorrelation analysis to describe hot and cold periods, but have not attempted to clearly identify structural breaks that separate different regimes (eg. Ibbotson et al. 1994, Loughran et al. 1994). As noted above, objective identification of the timing and characteristics of hot issue periods can help researchers to construct theories and empirical tests that attempt to explain the existence of such periods.

There are only a few explanations of hot issue periods that have been suggested in the literature. Ritter argued that the hot market of 1980 may have been attributable to small, natural resource issues since only these issues appeared excessively underpriced during the period. For instance, an average initial return of $21.0 \%$ for non-natural resource issues was observed during 1980 compared to $15.8 \%$ during other periods. Natural resource issues, in contrast, had an average initial return of $110.9 \%$ during 1980 compared to only $18.3 \%$ during other periods. By applying Rock's (1986) model, Ritter (1984) suggested a changing risk 
composition hypothesis to explain the 1980 hot issue market. He argued that if high risk IPOs represent an unusually large proportion of offerings in some specific periods, high average IPO underpricing should be observed in these periods. It is argued that natural resource issues are inherently of higher risk due to problems in valuation, increased information asymmetry and the industry's high level of business risk. Ibbotson and Ritter (1995) note, however, that the magnitude of swings in underpricing cannot be fully accounted for by changes in risk. The changing risk hypothesis also does not explain the related phenomenon of cycles in the volume of new issues.

A second explanation of hot periods concerns positive feedback strategies. Investors observe positive serial correlation in initial IPO returns and consequently assume that initial returns are likely to remain high if the price of recent issues has risen (Rajan and Servaes 1993). The argument is linked to similar arguments of investor sentiment used to explain apparent patterns in the stock market. However, these arguments do not explain how hot issue markets commence in the first place, and they rely upon investor irrationality or market inefficiency.

A recent paper by Loughran and Ritter (2000) provides a prospect theory explanation for hot issue markets that is consistent with rational behavior. Prospect theory implies that issuers care about the change in their wealth and thus are relatively unconcerned about specific underpricing if the net value of their holdings has risen, as would happen when unexpectedly strong demand appears during the pre-selling period. Loughran and Ritter (2000, p.3) argue that underpricing is an indirect form of compensation to underwriters, with issuing firms acquiescing to increased underpricing of their issues when the value of issuers' holdings (net of all underwriter compensation) has risen. The net value of holdings is strongly linked to the stock market itself such that a rise in the stock market leads to an increase in expected underpricing of all IPOs in the selling period. Further, overlapping selling periods induce positive serial correlation of first-day returns. Hence, this theory provides an insight as to how hot issue markets may commence.

Nevertheless, the questions of how frequently hot issue markets occur, what features are associated with these markets, and the dating of their occurrences, remain largely unanswered. While extant evidence supports the existence of hot issue markets, it is based on descriptive expost analysis, thus leaving an important role for techniques that can more 
objectively determine the timing and properties of hot and cold IPO markets.

\section{Research Method}

Objective determination of the existence of hot and cold periods in the IPO market requires the identification of a series of significant structural breaks in IPO activity and underpricing. Traditional econometric tests for structural change include the Chow test, the Cumulated Sum of Residuals (CUSUM) test and the CUSUM of Squares (CUSUMSQ) test. The Chow test requires prior knowledge (or at least a guess) of break points and sequential application of Chow tests is inefficient. If structural breaks cannot be identified ex-ante, then the strength of the Chow test diminishes considerably (Gujarati 1995). CUSUM and CUSUMSQ tests are appropriate for time-series data, and can be used to identify the existence of significant structural changes in a data set. However, the identification of significant structural breaks beyond a first regime shift requires an extension of the traditional CUSUM technique. Moreover, the Chow and CUSUM tests are statistical tests and do not provide a modeling device.

Markov-based regime-switching can be used to model time series subject to non-linear regime changes (Hamilton, 1989). The concept behind regime-switching is to allow the parameters of a time-series process to take on different values that are dependent on the latent regime indicator (denoted as $S_{t}$ ). The unobservable regime indicator takes on different states, although applications tend to restrict it to just two states. The data are used to estimate the parameters in each state as well as the probability that the underlying process is in a particular state. The parameters are viewed as the outcomes of a discrete-state Markov process. An important practical advantage of the regimeswitching model is its ability to quickly identify regime shifts, using all the data up to a specific period to form a judgment. The model can be used in the absence of perfect knowledge of historical regime shifts (Layton 1996). In the current context, the level of IPO activity may be subject to occasional and discrete shifts over time such that different regimes are observed. These regime shifts are the hot and cold issue periods.

Regime-switching models have recently been used in modeling 
nonlinear structure of financial time series. Schaller and Van Norden (1997) have used the technique and found strong evidence of regime switching in US stock market returns, while Hamilton and Lin (1996) have employed the model to capture nonlinear dynamics in the stock market and the business cycle. Gray (1996) has developed a regimeswitching model with time-varying properties and applied it to interest rates. In an application of the model, Hamilton (1989) used a two-state version of the model applied to US GNP data. In the model the economy is assumed to be in either of two states (a recovery or a recession). Hamilton's estimated parameters reproduce characteristics of the US business cycle.

Regime switching in the IPO market could arise in several ways. Changes in economic conditions might induce regime switches. Allen and Faulhaber (1989) have suggested, for instance, that the hot issue market in 1980 was associated with the 1979 oil crisis. More generally, changes in economic growth can affect growth in the corporate sector and consequently the propensity for firms to seek new equity from the market. Changes in investor sentiment might induce regime switches. Rajan and Servaes (1997) have argued that an increase in investor sentiment may increase the number of new issues. Mutual fund net cash flows have been used as a measure of investor sentiment (Neal and Wheatley 1998, Keim and Stambaugh 1986), and Ritter (1997) has suggested that hot issue markets might be related to increases in mutual fund net cash flows that raise the demand for securities such as IPOs. Regime switches could also be related to changes in stock market conditions. Loughran et al. (1994) and Rees (1997) have provided evidence of a positive relationship between stock market conditions and IPO activity. It is argued that issuers consider stock market conditions when timing their issues.

In the context of IPO markets, two regimes can be identified, a hot period (state 0 ) and a cold period (state 1). Therefore, the regime indicator, $S_{t}$, takes on the value of 1 when the IPO market is in a cold period and 0 when the IPO market is in a hot period. The probability that state 0 (1) will persist from one period to the next is given as $q(p)$. The probability of moving from state 0 to state 1 is $1-q$, and moving from state 1 to state 0 is $1-p$. The regime is assumed to be unknown and independent across time. For each regime, the probability rule to govern the likelihood of various observations is the normal density function, with 
different means $\left(a_{01}\right.$ and $\left.a_{02}\right)$ and variances $\left(\sigma_{1}\right.$ and $\left.\sigma_{2}\right)$. Hence, in hot periods, IPO activity measures are drawn from a distribution with a mean $a_{01}$ and standard deviation $\sigma_{2}$, while in cold periods, IPO activity measures are drawn from a distribution with a mean $a_{01}$ and standard deviation $\sigma_{2}$. Thus, each regime is characterized by a different mean and standard deviation. The conditional distribution is then a mixture of normals.

Formally, let $Y_{t}$ denote any measure of IPO activity, then:

$$
Y_{t}=a_{01}\left(1-S_{t}\right)+a_{02} S_{t}+\left[\sigma_{1}\left(1-S_{t}\right)+\sigma_{2} S_{t}\right] \varepsilon_{t},
$$

where $S_{t}$ is a binary state variable that follows a first-order Markov Chain such that:

$$
\begin{gathered}
\operatorname{Pr}\left(S_{t}=0 \mid S_{t-1}=0\right)=q, \\
\operatorname{Pr}\left(S_{t}=1 \mid S_{t-1}=0\right)=1-q, \\
\operatorname{Pr}\left(S_{t}=1 \mid S_{t-1}=1\right)=p, \\
\operatorname{Pr}\left(S_{t}=0 \mid S_{t-1}=1\right)=1-p,
\end{gathered}
$$

and,

$$
\varepsilon_{t} \sim N\left(0, \sigma^{2}\right)
$$

To obtain estimates of the parameter vector $\left(a_{01}, a_{02}, \sigma_{1}\right.$ and $\left.\sigma_{2}\right)$, maximum likelihood estimation can be used (Hamilton, 1989). The maximum likelihood estimate of the two transition probabilities (1- $q$ and $1-p)$ is the fraction of time that the system is in one state before moving to another state. In other words, the estimated transition probability, 1-q, is the number of times state 0 is followed by state 1 divided by the number of times the process is in state 0 . The benefit of using the above process in modeling regime switching in IPO activity is that it allows investors to generate meaningful forecasts that take into account the possibility of the change from one regime to another. Furthermore, the transition probabilities obtained help to assess the duration of each regime. For instance, the expected duration of hot issue cycles is 
obtained by calculating $(1-q)^{-1}$ and, conversely, for cold issue cycles the duration is calculated as $(1-p)^{-1}$.

\section{Data}

The IPO data set is constructed using files maintained by the Securities Data Corporation (SDC) on all registered security issues in the United States. These files are based primarily on information filed with the Securities and Exchange Commission (SEC) in public registration statements. Share price data are obtained from a combination of sources - SDC, Center for Research in Security Prices (CRSP) and Datastream International.

The following sample selection criteria are employed:

The IPO must be a common stock IPO. Issues under Rule 144A, Private Placements and Shelf Registrations are excluded from the data set;

Closed-end mutual funds and Real Estate Investment Trusts (REITs) are excluded; ${ }^{2}$

Unit offerings are excluded; ${ }^{3}$

A US based firm must issue the IPO.

A final sample of 6,632 IPOs is obtained for the period January 1976 to June 1998. Given data constraints, the sampling frequency is monthly. Summary statistics for the sample are presented in table 1. In this table, it can be seen that the number of offerings peaked in 1996 after

2. Closed-end mutual funds and REITs tend to be overpriced rather than underpriced (Peavy 1990, Wang et al. 1992, Nelling et al. 1995, Sirmans et al. 1987). This paper follows Ibboston et al. (1994) in excluding closed-end mutual funds and REITs from the sample.

3. Unit offerings are complex instruments that consist of a bundle of common stock offerings and other securities (usually warrants) sold together as a package. Unit offerings are removed from the sample due to differences in underpricing between unit and stock IPOs as well as complexities involved in valuing unit offerings (Schultz 1993, Jain 1994). 
TABLE 1. Descriptive Annual Statistics of IPOs Classified by Year

\begin{tabular}{|c|c|c|c|c|}
\hline & $\begin{array}{l}\text { Number. of } \\
\text { Offerings }\end{array}$ & $\begin{array}{l}\text { Average Initial } \\
\text { Return }\end{array}$ & $\begin{array}{l}\text { Gross Proceeds } \\
\text { (US \$ Mil.) }\end{array}$ & $\begin{array}{c}\text { Average Proceeds } \\
\text { (US \$ Mil.) }\end{array}$ \\
\hline 1976 & 37 & .00767 & 260 & 7.0 \\
\hline 1977 & 24 & .07988 & 138 & 5.7 \\
\hline 1978 & 34 & .12095 & 210 & 6.2 \\
\hline 1979 & 58 & .08137 & 377 & 6.5 \\
\hline 1980 & 120 & .28509 & 1,173 & 9.8 \\
\hline 1981 & 291 & .13473 & 2,765 & 9.5 \\
\hline 1982 & 97 & .10457 & 1,152 & 11.9 \\
\hline 1983 & 574 & .10187 & 11,662 & 20.3 \\
\hline 1984 & 251 & .04236 & 2,770 & 11.0 \\
\hline 1985 & 270 & .04661 & 5,996 & 22.2 \\
\hline 1986 & 561 & .06133 & 16,658 & 29.7 \\
\hline 1987 & 400 & .06003 & 12,399 & 31.0 \\
\hline 1988 & 158 & .06846 & 4,664 & 29.5 \\
\hline 1989 & 135 & .09205 & 4,807 & 35.6 \\
\hline 1990 & 131 & .10785 & 4,122 & 31.5 \\
\hline 1991 & 302 & .12294 & 14,203 & 47.0 \\
\hline 1992 & 415 & .10739 & 19,747 & 47.6 \\
\hline 1993 & 525 & .12748 & 26,550 & 50.6 \\
\hline 1994 & 414 & .09215 & 15,180 & 36.7 \\
\hline 1995 & 462 & .21576 & 23,947 & 51.8 \\
\hline 1996 & 695 & .17302 & 37,600 & 54.1 \\
\hline 1997 & 471 & .14815 & 26,900 & 57.1 \\
\hline 1998 & 207 & .14646 & 14303 & 69.1 \\
\hline Total & 6,632 & 10192 & 247,583 & 29.6 \\
\hline
\end{tabular}

Note: The sample is based on 6,632 unseasoned offerings listed in the USA during the period January 1976 to June 1998. The figures for 1998 are only for half-year. Average initial return is calculated as the return of the closing price on the first day of trading from the offer price averaged across IPOs.

increasing sharply over most of the sample period. The average size of offerings also increased sharply from US\$7.0 million in 1976 to US\$69.1 million in 1998, with the sample average being $\$ 29.6$ million. The monthly average of initial returns on the first day of listing ranges from .77\% in 1976 to $28.51 \%$ in 1980, with the average for the overall sample being $10.19 \%$. These figures are slightly lower than results from earlier time periods such as a 15.26\% average initial return for the period 1960-1992 (Ibbotson et al. 1994). 


\section{Measures of IPO Activity}

IPO activity has traditionally been viewed in terms of three measures a volume measure such as the number of IPO issues, a pricing measure such as the average level of underpricing, and a value measure such as the total value of new issues. This paper examines the three traditional measures of IPO activity as well as a fourth measure, the total value of underpricing, which captures the economic importance of IPO underpricing. The volume measure, the number of IPOs per month (NOIPO), expressed as a percentage of the total number of IPOs in the data set, is consistent with previous work (eg. Ibbotson et al. 1994, Loughran et al. 1994). The total value measure, the inflation-adjusted gross value of IPO proceeds per month (GP), is also expressed as a percentage of total proceeds in the entire data set and is also consistent with the literature (Rees 1997). ${ }^{4}$ Taken together, these activity measures indicate how many IPOs occurred in a month and whether the IPOs that occurred during the month were important from a value perspective.

The IPO underpricing measure used in this paper, value-weighted underpricing $(V U P)$, improves upon previous measures of underpricing by weighting each issue's contribution to monthly underpricing according to the relative size of the issue within the month:

$$
V W U P_{t}=\frac{\sum_{i=1}^{N}(\text { proceeds })_{i, t} \times(\text { IPO Underpricing })_{i, t}}{\sum_{i=1}^{N}(\text { proceeds })_{i, t}} \times 100,
$$

where $t=$ month $1,2, \ldots, T$ where $T=270 ; i=$ company $1,2, \ldots, N$ where $N$ is the number of IPOs in month $t$; (proceeds) $)_{i, t}=[($ number of

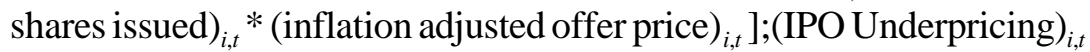
$=\left[(\text { closing price on first day trading })_{i, t}-(\text { offer price })_{i, t}\right] /(\text { offer price })_{i, t}$.

4. The inflation adjustment is the level of IPO activity divided by an inflation index, where the inflation index is measured each month using January 1976 as the base month. The inflation rate data are obtained from the Federal Reserve Bank of St Louis. 
This measure avoids the problem whereby traditional arithmetic average measures of underpricing are subject to too much influence from small 'penny' stocks (Ibbotson and Ritter 1995). ${ }^{5}$

The final measure of IPO activity, the value of underpricing $(V U P)$, measures the total value of underpricing in a particular month divided by the total value of underpricing in the entire sample (expressed as a percentage), thereby indicating whether underpricing in a particular month is economically important:

$$
V U P_{t}=\frac{\sum_{i=1}^{N}(\text { proceeds })_{i, t} \times(\text { IPO Underpricing })_{i, t}}{\sum_{t=1}^{T} \sum_{i=1}^{N}(\text { proceeds })_{i, t} \times(\text { IPO Underpricing })_{i, t}} \times 100 .
$$

Taken together, the two underpricing measures indicate whether underpricing occurred in a particular month as well as whether the underpricing was important (see also Loughran and Ritter, 2000).

Summary statistics for the four IPO activity measures are reported in table 2. The relative number of IPOs (NOIPO) ranges from a low of zero (ie. no issues) to a monthly high of $1.36 \%$, and the relative proportion of gross proceeds ranges from zero to $2.11 \%$. The underpricing series exhibit greater volatility, as expected. The average $V W U P$ per month is $8.67 \%$, thus implying larger issues are less underpriced since this figure is lower than the simple sample average for underpricing of $10.19 \%$ (see table 1). Monthly VWUP ranges from underpricing of $70.38 \%$ to overpricing of $15.56 \%$. In the last column of table 2, test statistics for the Dickey-Fuller test for stationarity are presented. These results suggest that each of the four series is stationary.

Figures 1a to $1 \mathrm{~d}$ present graphs of the four measures of IPO activity.

5. A monthly index of equal weighted underpricing is also constructed. This index is highly correlated with the value weighted underpricing index $($ correlation $=.8972)$. 
TABLE 2. Summary Statistics of Measures of IPO Activity

\begin{tabular}{|c|c|c|c|c|c|}
\hline & Mean & $\begin{array}{l}\text { Standard } \\
\text { Deviation }\end{array}$ & Min & Max & $\begin{array}{l}\text { Dickey- Fuller } \\
\text { Test Statistic }\end{array}$ \\
\hline NOIPO & .3704 & .3011 & .0000 & 1.3571 & $-2.88 *$ \\
\hline$G P$ & .3704 & .4017 & .0000 & 2.1132 & $-2.87^{*}$ \\
\hline$V W U P$ & 8.6667 & 9.4220 & -15.5557 & 70.3829 & $-6.44 *$ \\
\hline$V U P$ & .3704 & .6092 & -.2064 & 4.8029 & $-3.39 *$ \\
\hline
\end{tabular}

Note: The sample is based on 6,632 unseasoned offerings listed in the USA over January 1976 to June 1998. NOIPO represents the percentage of unseasoned issues in each month; $G P$ is a percentage measure of the gross proceeds raised from unseasoned issues each month; VWUP is a value-weighted underpricing measure; VUP is a measure of total value of underpricing in each month relative to the sample. The Dickey-Fuller test statistic is a test of stationarity in each series. Note the means for NOIPO, GP and VUP are a proportional function over the sample period. *Denotes significance at the $5 \%$ level.

In figure 1a, NOIPO shows a clear pattern of active and inactive periods of activity prior to 1991, with spikes in 1981, 1984 and 1987. The series becomes more volatile after 1991. Figure $1 \mathrm{~b}$ shows that gross proceeds (GP) generally follows the pattern of the NOIPO series, although it is interesting to note the period 1980-81 during which time peaks in GP are generally of a much smaller relative magnitude than the peaks in NOIPO. This observation supports Ritter's (1984) argument that this period was driven by a relatively large number of small issues.

Casual observation suggests that the two underpricing series, illustrated in figures $1 \mathrm{c}$ and $1 \mathrm{~d}$, do not track the volume and gross proceeds series particularly well. The two underpricing series also reveal important differences. Figure 1c, which plots the $V W U P$ series, reveals large spikes around 1979, 1980, 1981, 1983 and a generally high level from around 1989 onward. The large spikes during 1980-81 may be surprising, and are of a considerably greater magnitude than the spikes in the VUP series illustrated in figure $1 \mathrm{~d}$. This may be explained by the observation that most issues around this time period were small, hence underpricing of small issues was relatively important within these months even though the total value of underpricing during these months was unimportant overall.

Figure 1d indicates that the pattern of $V U P$ is more consistent with the volume series pattern than is the $V W U P$ pattern. The $V U P$ series 

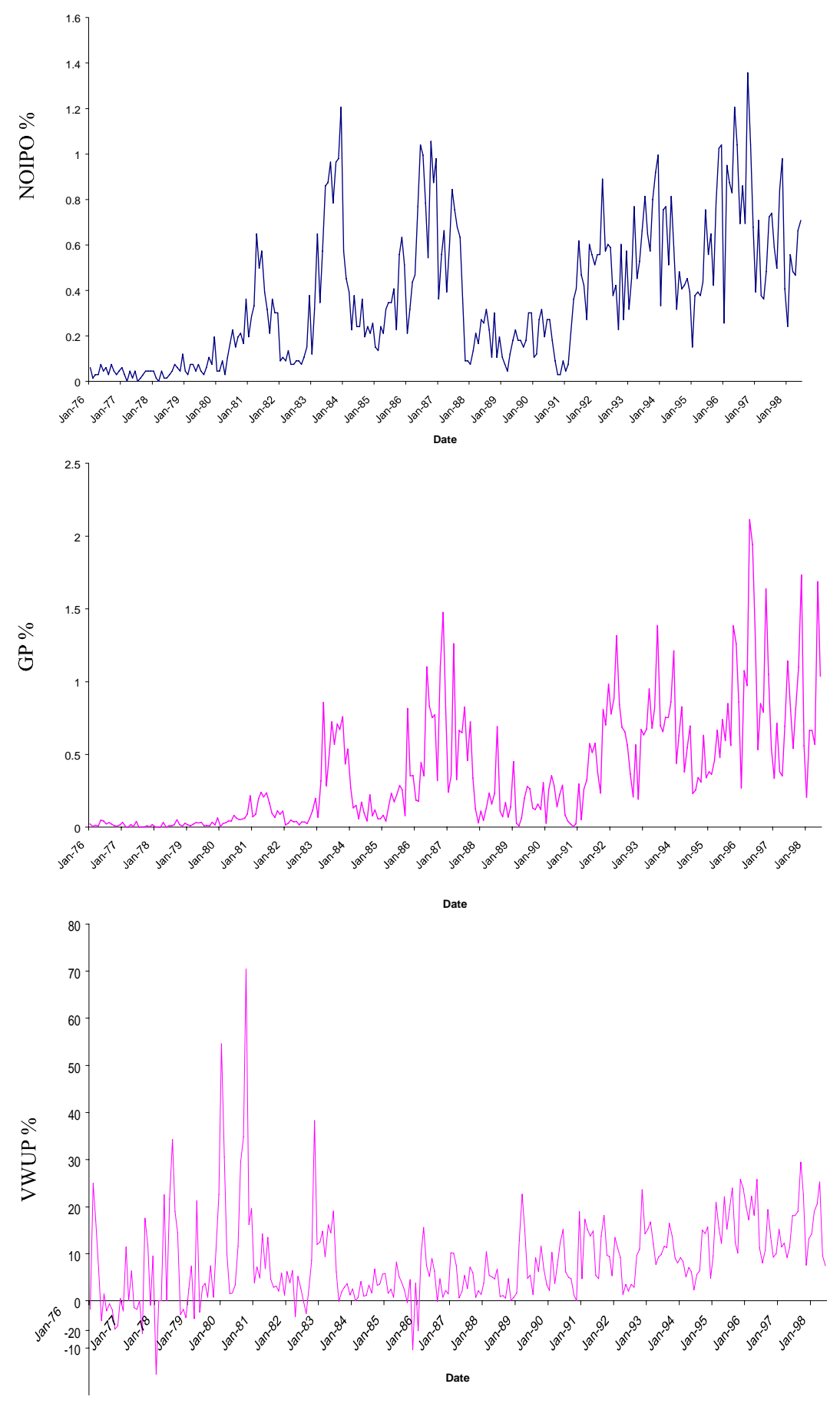


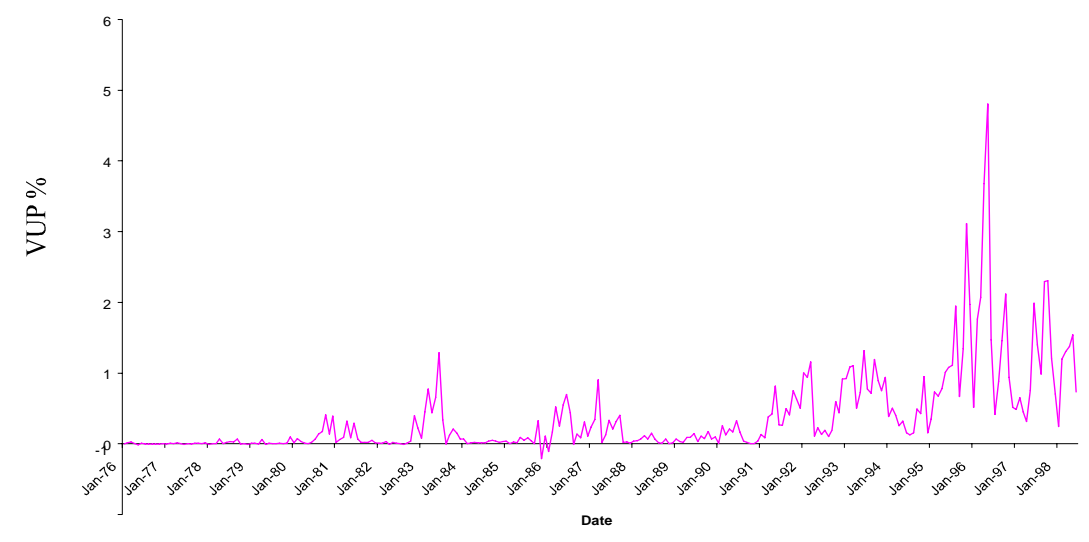

FigURE 1.- NOIPO, GP, VWUP and VUP, during the period January 1976 to June 1998

exhibits some small spikes around 1983 and 1987 and then reaches a high but relatively stable level throughout the 1990s, with some large values around 1996. Also of note, spikes in the VUP series appear to lead spikes in the volume and gross proceeds series by up to a year.

\section{Regime Switching Results}

CUSUM and CUSUMSQ tests conducted on the four IPO activity measures to ascertain the existence of structural breaks provide strong evidence that structural breaks exist in each series. ${ }^{6}$ The Markov regime-switching model is then applied to determine the turning points between regimes that are initially suggested by the CUSUM and CUSUMSQ tests.

The parameter estimates of the Markov regime-switching model for each of the four series are provided in table 3. A common characteristic across all of the IPO activity measures is the observation of higher means and standard deviations in hot periods than in cold periods. For instance, the proportion of the number of issues per month (NOIPO) in hot periods is $.59 \%$ of the sample with a standard deviation of $.25 \%$. In

6. The results of these tests are not reported here but are available upon request. 


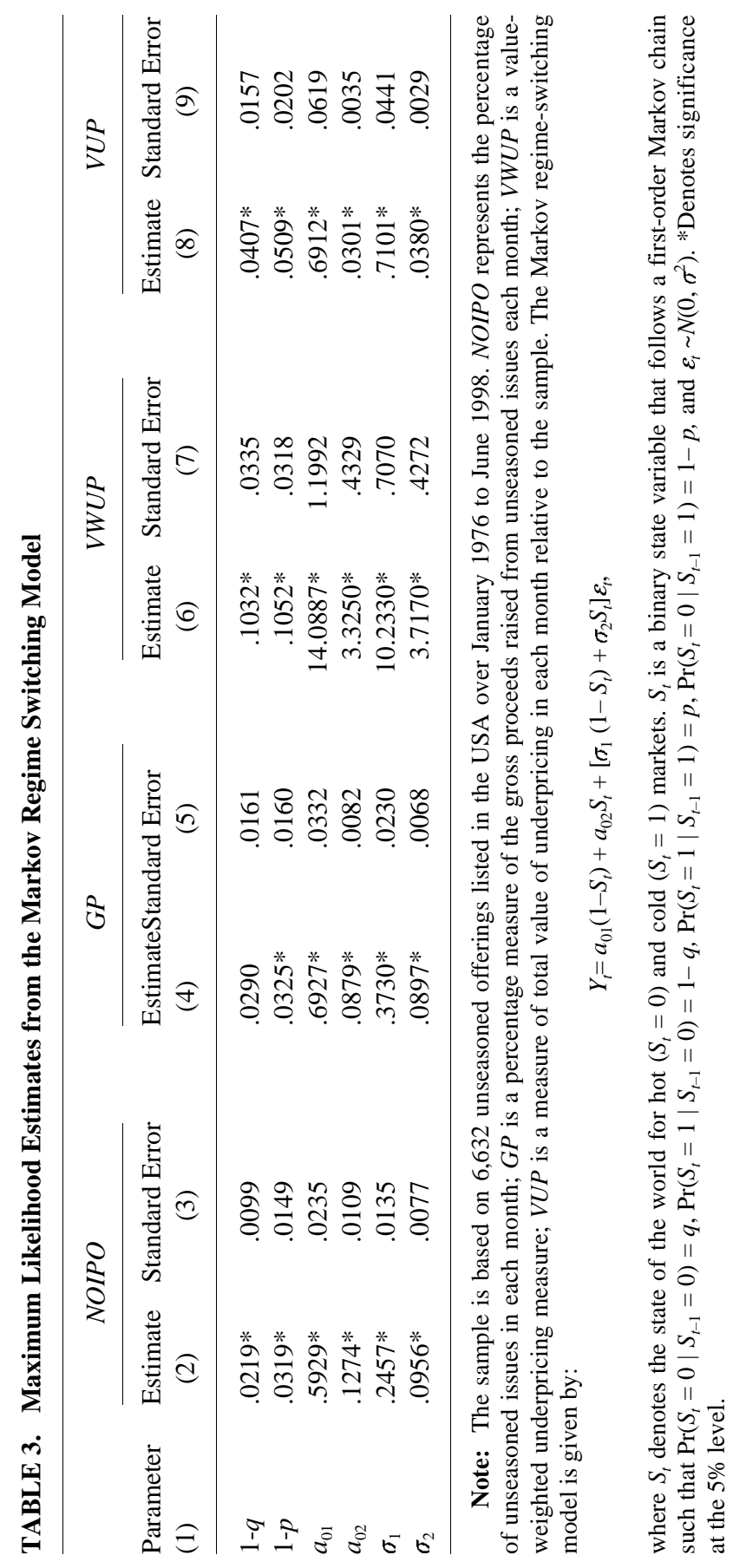


comparison, the average proportion of the number of issues is almost five times lower in cold periods $(.13 \%)$ with much lower volatility (standard deviation of .1\%). Significant differences between regimes are also obtained for GP where the average proportion of gross proceeds per month in hot periods is .69\% of the sample compared to only $.09 \%$ in cold periods. Again, the standard deviation of GP is much higher in hot periods than cold periods (.37\% vs $.09 \%)$.

The two underpricing measures also exhibit substantially different parameters between the two regimes. VWUP is $14.09 \%$ on average in hot periods but only $3.33 \%$ in cold periods. VUP is $.69 \%$ in hot periods compared to only . $03 \%$ in cold periods. The standard deviations reflect similar patterns.

In summary, hot periods are characterized by substantially higher means and standard deviations than cold periods in all of the IPO activity and underpricing series.

The estimated regime probabilities for each data point are shown in figures $2 \mathrm{a}$ to $2 \mathrm{~d}$. These probabilities are used to determine the timing of shifts in each of the activity measures. A regime switch is defined as having occurred if the probability of being in the new state is greater than .5 for at least six consecutive months. The rationale for this rule is that hot and cold periods are likely to be driven by fundamental shifts in economic factors or investor sentiment. Such shifts are likely to have a temporal effect greater than one month. Moreover, institutional and regulatory features induce lags between the corporate manager's decision to issue and the listing date. These lags have been estimated to be somewhere between three to six months (Lipman 1997). Given that market conditions are likely to influence the manager's decision, temporal swings of less than six months are not especially relevant. ${ }^{7} \mathrm{~A}$ similar widely accepted "six-month" rule is used by the National Bureau of Economic Research (NBER) to determine the minimum length of a phase of the business cycle. Hot and cold issue periods are identified using the regime probabilities and the above transition rules, and are reported in table 4 and figure 3 .

To further illustrate the difference between hot and cold issue periods, table 5 provides the differences in means and standard

7. Alternative state definitions were employed including probabilities of greater than .5 for at least three consecutive observations; the conclusions remain unchanged. 
TABLE 4. Chronology of IPO Activity Based on Transition Probabilities from the Regime Switching-Model

\begin{tabular}{ll}
\hline Hot Periods & Cold Periods \\
\hline Number of IPOs $($ NOIPO) & \\
Apr 81 - Dec 81 & Jan $76-$ Mar 81 \\
Mar 83 - Sep 84 & Jan $82-$ Feb 83 \\
Jul 85 - Nov 87 & Oct $84-$ Jun 85 \\
May 91 - Jun 98 & Dec $87-$ Apr 91 \\
Gross Proceeds $(G P)$ & \\
Mar 83 - Feb 84 & \\
Oct 85 - Nov 87 & \\
May 91 - Jun 98 & Jan $76-$ Feb 83 \\
Value-Weighted IPO Underpricing $(V W U P)$ & Mar $84-$ Sep 85 \\
Sep 77 - Oct 78 & Dec $87-$ Apr 91 \\
Aug 80 - Jul 81 & \\
Nov 82 - Jul 83 & \\
Dec 90 - Mar 92 & \\
Nov 92 - Jun 98 & Jan $76-$ Aug 77 \\
Value of Underpricing $(V U P)$ & Nov $78-$ Jul 80 \\
Nov 82 - Dec 83 & Aug $81-$ Oct 82 \\
Oct 85 - Sep 87 & Aug $83-$ Nov 90 \\
Feb 90 - Jul 90 & Apr $92-$ Oct 92 \\
Mar 91 - Jun 98 & \\
\hline & \\
\hline
\end{tabular}

Note: The sample is based on 6,632 unseasoned offerings listed in the USA over January 1976 to June 1998. NOIPO represents the percentage of unseasoned issues in each month; $G P$ is a percentage measure of the gross proceeds raised from unseasoned issues each month; VWUP is a value-weighted underpricing measure; VUP is a measure of total value of underpricing in each month relative to the sample. Transition probabilities are taken from the Markov regime-switching model given by:

$$
Y_{t}=a_{01}\left(1-S_{t}\right)+a_{02} S_{t}+\left[\sigma_{1}\left(1-S_{t}\right)+\sigma_{2} S_{t}\right] \varepsilon_{t},
$$

where $S_{t}$ denotes the state of the world for hot $\left(S_{t}=0\right)$ and cold $\left(S_{t}=1\right)$ markets. Transition rules are invoked such that a hot period requires the probability of $S_{t}=1$ exceeding $50 \%$ for at least six consecutive months. 




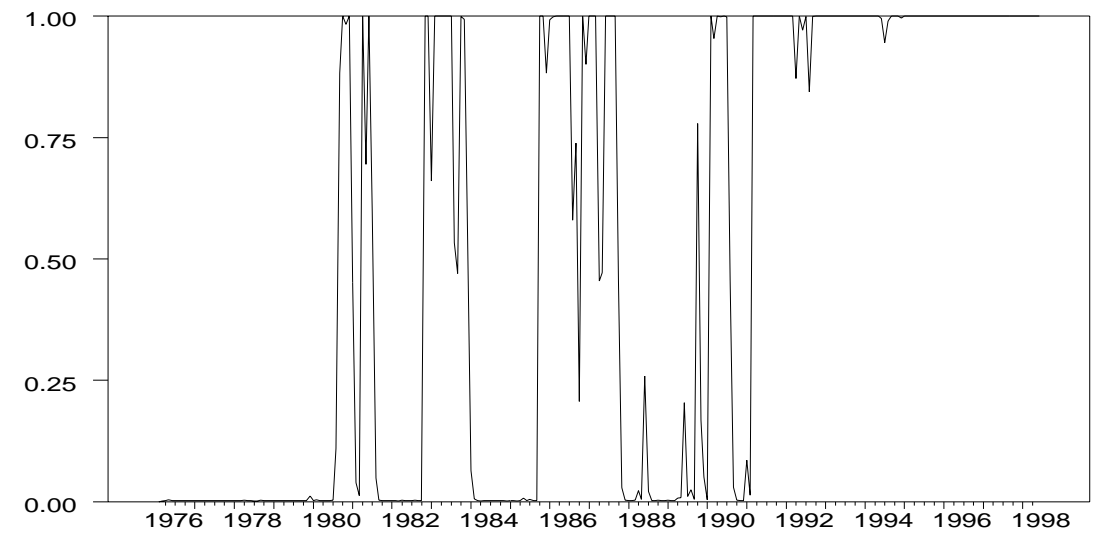

FIGURE 2.- Regime probability of being in hot periods for NOIPO, GP, VWUP, and VUP

deviations across the four IPO activity measures. The table indicates that for all the IPO activity measures, the estimated means and standard deviations for hot periods are significantly different from the estimated means and standard deviations for cold periods. The results indicate that the regimes are fairly stable once in place, thus demonstrating that the procedure could also be used as a method to identify the current state of the IPO market using current market conditions.

The two volume measures of NOIPO and GP exhibit similar hot issue periods as evidenced in table 4 . The calendar periods identified as hot are almost identical between these measures, except for the period of April to December 1981, where NOIPO is in a hot state and GP is in a cold state. Of note, the crash of October 1987 has a strong influence on the market with both volume measures shifting to a cold state in November 1987 that lasts until May 1991. Interestingly, the regimeswitching model does not identify the hot issue period of 1980 observed by Ritter (1984) mainly because the large number of IPOs in the 1990s reduces the relative influence of the earlier 1980 period. Note that the expected duration of a hot issue period is 46 months using NOIPO and 35 months using $G P{ }^{8}$

8. The expected duration of each hot issue cycle can be calculated using $(1-q)^{-1}$ and, conversely, for cold issue cycles it is calculated as $(1-p)^{-1}$ 


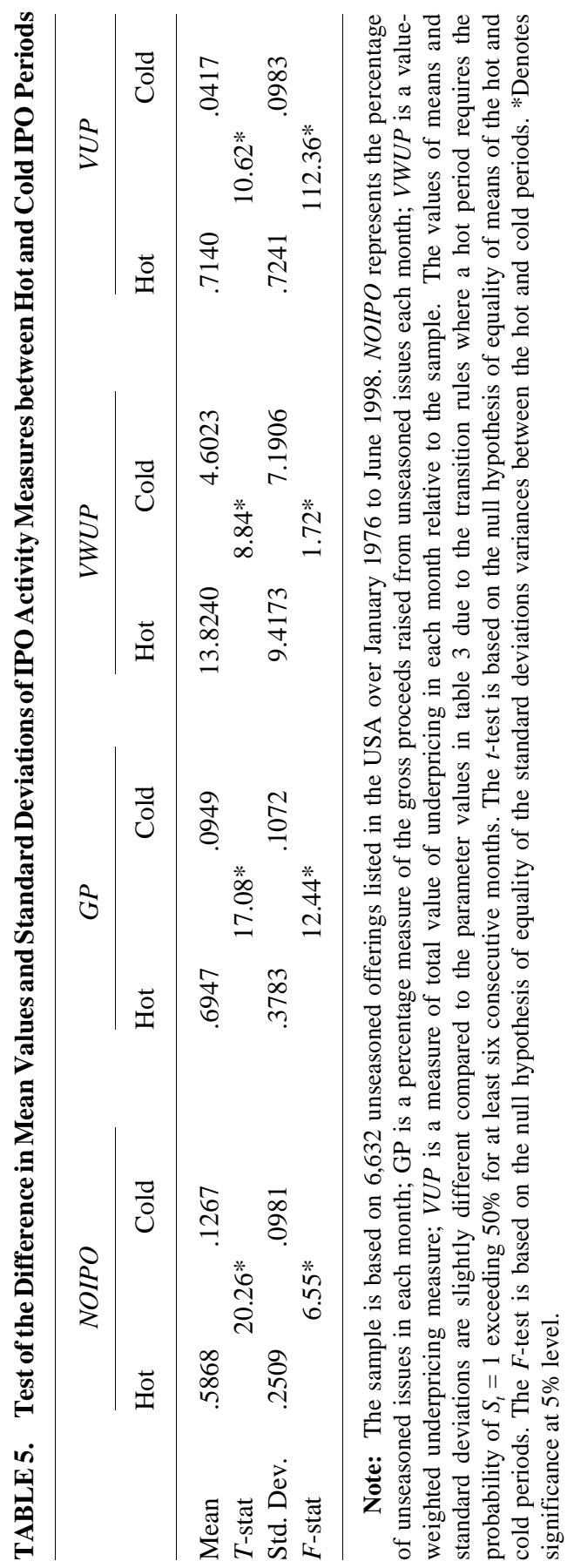




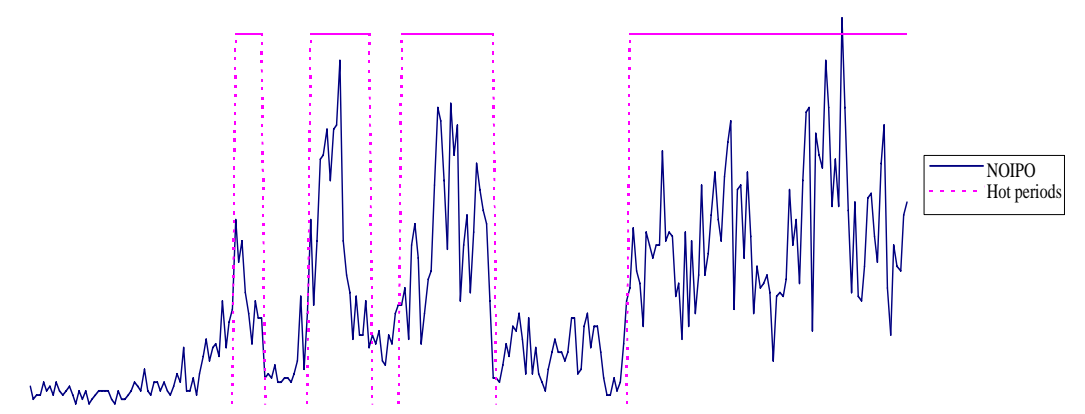

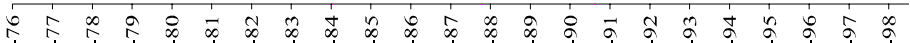

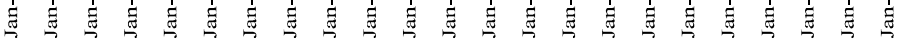
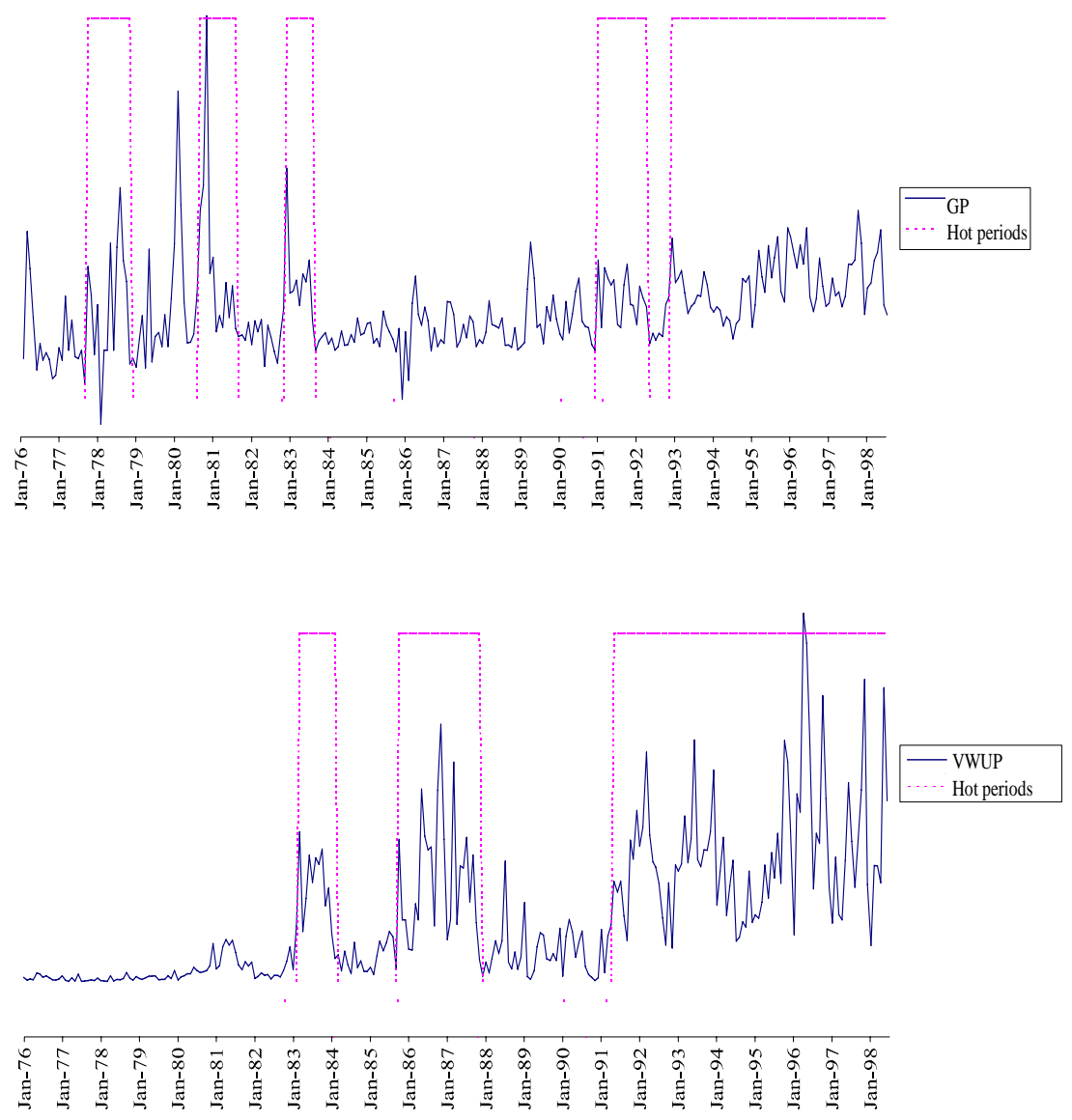




FIGURE 3.- Dated Hot Issue Periods based on Transition Probabilities from a Regime-Switching Model for IPO Activity Measures

In contrast, the two underpricing measures give different signals. $V W U P$ provides a greater frequency of transitions wherein hot periods appear more volatile and less persistent compared to VUP. The expected duration of a hot period using $V W U P$ is only 10 months compared to 24 months using VUP. The hot period identified by $V W U P$ over August 1980 to July 1981 is consistent with the hot issue period observed by Ritter (1984). ${ }^{9}$ The finding of a hot state in this period using VWUP but not for the other measure is further support for Ritter's (1984) argument that small issues drove the high degree of IPO underpricing in 1980. VWUP is the only measure that does not identify a hot period immediately prior to the crash in 1987. In comparison, VUP identifies a hot period between October 1985 and September 1987 ending one month before the crash, even though the hot period in the volume measures persisted until November 1987. This difference between the underpricing and volume measures around the crash may be explainable through the difficulty in recalling an issue once it has commenced. Hence, the volume measures are not as dynamic in their response as price-based measures such as VUP. The persistence in the volume measures during adverse market conditions supports the argument that even if issuers respond to market conditions when making timing decisions, the lag induced by institutional and regulatory

9. The hot issue period observed by Ritter (1984) was January 1980 to March 1981. 
requirements exposes issuers to the risk of issuing during market downturns.

A casual observation of table 4 and figure 3 indicates lead-lag features between the volume and underpricing measures. Specifically, the hot periods in the underpricing measures appear to lead the hot periods in the volume measures. For example, hot periods in VWUP commenced in August 1980, November 1982, and March 1983 followed by hot periods in NOIPO in April 1981, March 1983, and May 1991, respectively. This feature is explored further in the next section.

The most common hot issue period observed across all measures of IPO activity is May 1991 to June 1998, thus providing evidence of a correlation between IPO activity and stock market conditions. ${ }^{10}$ All IPO activity measures indicate a sustained hot issue period between 1991 and 1998, a time period that is also associated with strong business conditions. In the next section these issues are explored further by examining the relationships among IPO activity series and economic conditions.

\section{Explanatory Relationships}

The regime-switching results suggest a potential lead-lad relationship between the volume and underpricing measures as well as correlations among IPO activity and market conditions. The paper now first examines the lead-lag features in the IPO market itself. Spearman correlation tests are used to test the lead-lag relationship between the estimated probabilities for the IPO volume and underpricing series. ${ }^{11}$ Table 6 reports the Spearman Rank correlation coefficients between current and lagged estimated probabilities of the main volume series

10. Recall that most of the 1990s represented a sustained bull market. Choe et al. (1993), using US data from 1971 to 1991, also document that the frequency of seasoned offerings rises in economic upturns. They argue that firms will issue equity when the effects of adverse selection are less important due to improved business conditions.

11. The power of conventional tests (such as OLS based tests) is limited by the nature of the probability distributions, as by definition the probabilities lie between zero and one. Hence the Spearman correlation test is used. 
$(N O I P O)$ and underpricing series $(V W U P)$.

From table 6 , there is evidence of a contemporaneous correlation between the two series. The estimated probabilities of $V W U P$ show no correlation with lagged probabilities of $N O I P O$, but the probabilities of $N O I P O$ show strong correlation with lagged probabilities of $V W U P$ up to six months. This evidence supports a lead-lag relationship from underpricing to IPO volume. The finding supports the argument that the decision to issue is a function of current observed underpricing (also see Firth 1997, Ibbotson et al. 1988, 1994, Loughran and Ritter 2000, Rock 1986). The lead from underpricing to IPO volume may be explained as follows. When potential issuers observe high levels of current underpricing, they take this as an indication of improved valuations and seek to take advantage of these conditions. Issuers are thus seen to be exploiting "windows of opportunity" (Ibbotson et al. 1994, Loughran et al. 1994). However, IPO issuers cannot respond immediately to market conditions due to a three- to six-month lag during which time various activities are undertaken to fulfil legal requirements and promote the issue (Lipman 1997). This institutional induced lag then creates correlations over several months.

An alternative explanation for the lead of underpricing to IPO volume concerns the role of underwriters and promoters. Issuers, particularly novice issuers, often rely upon the advice of their underwriter in timing their issue. If underwriters perceive improved market conditions they may be able to convince issuers to go public by informing them that proceeds will be greater than initially thought, thus leading to increased new issue volume following periods of underpricing (Loughran and Ritter 2000). Improved market conditions also allow underwriters the opportunity to underprice an issue, thus providing them with the opportunity to offer "stag" profits to valued clients.

The regime-switching results and the above arguments suggest that the stock market and business conditions impact on the relationship between the underpricing and volume series. Specifically, given our arguments above, the valuation indicator provided by current underpricing suggests that the stock market itself has a role to play. This issue is investigated through the use of a vector auto-regression (VAR).

Three variables are selected to measure market and business conditions. They are the term premium, the monthly percentage change 





in the business cycle as proxied by the NBER index of leading indicators, and the monthly percentage change in the S\&P 500 index. ${ }^{12}$ The selection of these variables is guided by theory and prior empirical evidence.

As discussed above, Loughran et al. (1994) hypothesize that IPOs are timed to take advantage of windows of opportunity created when the stock market is rising and investors place high valuations on the future growth opportunities of firms. Choe et al. (1993) developed a model in which firms choose between issuing equity and debt across business cycle expansions and contractions. They observed that, in general, a firm will issue equity when the stock market is high and will avoid issuing equity when the stock market is undervalued (see also Myers and Majluf 1984). Business expansions are also associated with more profitable investment opportunities that can lead to IPOs. Finally, Chen et al. (1986) have argued that the term premium is a reasonable measure of future business conditions. Harvey (1988) has further suggested that the term premium is a useful predictor of future economic growth and is more accurate than either the share market or prior values of GDP.

Interest rates on 10-year Treasury bonds and 3-month Treasury bills are used to measure long-term and short-term interest rates. ${ }^{13}$ The term premium is calculated using the monthly interest rate on the 10-year Treasury bond less the monthly interest rate on the 3-month Treasury bill. The form of the VAR is:

$$
\begin{gathered}
N O I P O_{t}=a_{1}+\sum_{j=1}^{m} \beta_{j} N O I P O_{t-j}+\sum_{j=1}^{m} \chi_{j} V W U P_{t-j} \\
+\sum_{j=1}^{m} \delta_{j} T P_{t-j}+\sum_{j=1}^{m} \phi_{j} S P_{t-j}+\sum_{j=1}^{m} \varphi_{j} B C I_{t-j}+\mu_{1, t},
\end{gathered}
$$

12. Dickey-Fuller stationary tests are conducted on these three variables and the results indicate that they are all stationary.

13. The data are collected from the Federal Reserve Bank of St Louis. 


$$
\begin{gathered}
V W U P_{t}=a_{2}+\sum_{j=1}^{m} \gamma_{j} V W U P_{t-j}+\sum_{j=1}^{m} \eta_{j} N O I P O_{t-j} \\
+\sum_{j=1}^{m} \varpi_{j} T P_{t-j}+\sum_{j=1}^{m} \theta_{j} S P_{t-j}++\sum_{j=1}^{m} \psi_{j} B C I_{t-j}+\mu_{2, t},
\end{gathered}
$$

where, $T P_{t}$ denotes the term premium in percentage terms; $S P_{t}$ denotes the monthly percentage change in the $\mathrm{S} \& \mathrm{P} 500$ index; $B C I_{t}$ denotes the monthly percentage change in the business cycle leading indicator; $m$ is the number of lags; $\mu_{1, t}$ and $\mu_{2, t}$ are the error terms.

A critical issue in VAR analysis is selection of the number of lags to be included in the model. The selection of the appropriate lag length is important because degrees of freedom are wasted if the lag length is too large and the model is mis-specified if the lag length is too small. A rule is applied whereby the selection of lag length is determined by minimising the Akaike Information Criteria (AIC) subject to the elimination of residual autocorrelation. ${ }^{14}$ In the event that the AIC is unable to distinguish clearly between alternative lag specifications, the likelihood ratio test for reduction in the number of lags in the VAR model is used. Based on these criteria, a VAR model with thirteen lags is used.

Diagnostic results on the VAR analysis are reported in table 7 , including $R$-square, $F$-statistic and Wald tests. ${ }^{15}$ The Wald tests focus on the statistical impact of each of the explanatory variable groups (NOIPO, VWUP, TP, SP and BCI) included in the regressions. Given the possibility of multi-colinearity, emphasis on individual $t$-tests might be misplaced so the Wald tests form the basis of the following discussion. The Wald tests utilize White's adjusted covariance matrix to correct for heteroskedasticity.

From table 7, some of the lagged dependent variable coefficients are statistically significant in both regressions (results not reported), and the

14. AIC is a goodness-of-fit measure that can be used to compare one model to another, with lower values indicating a more desirable model.

15. Given the number of parameters in the 13-lag model, their estimated values are not reported here. 
TABLE 7. Diagnostic Results of VAR Analysis on IPO Activity Measures and Economic Variables

\begin{tabular}{lcccc}
\hline Dependent Variable & NOIPO & & & $V W U P$ \\
\hline$R$-square & .812 & & & .544 \\
Adjusted $R$-square & .748 & & .389 \\
$F$-statistic & $12.701 *$ & & $3.507 *$ \\
\hline Wald-Tests & Chi-square & Prob. & Chi-square & Prob. \\
\hline Lagged NOIPO & $179.635^{*}$ & .000 & 13.654 & .399 \\
Lagged $V W U P$ & $21.829 * *$ & .058 & $56.670^{*}$ & .000 \\
Lagged $T P$ & $20.778^{* *}$ & .077 & 15.928 & .253 \\
Lagged $S P$ & $41.835^{*}$ & .000 & $29.545^{*}$ & .005 \\
Lagged $B C I$ & 8.639 & .800 & 13.768 & .390 \\
\hline
\end{tabular}

Note: The sample is based on 6,632 unseasoned offerings listed in the USA over January 1976 to June 1998. The VAR takes the form:

$$
\begin{gathered}
N O I P O_{t}=a_{1}+\sum_{j=1}^{13} \beta_{j} N O I P O_{t-j}+\sum_{j=1}^{13} \chi_{j} V W U P_{t-j} \\
+\sum_{j=1}^{13} \delta_{j} T P_{t-j}+\sum_{j=1}^{13} \phi_{j} S P_{t-j}+\sum_{j=1}^{13} \varphi_{j} B C I_{t-j}+\mu_{1, t},
\end{gathered}
$$

and

$$
\begin{aligned}
& V W U P_{t}=a_{2}+\sum_{j=1}^{13} \gamma_{j} V W U P_{t-j}+\sum_{j=1}^{13} \eta_{j} N O I P O_{t-j} \\
& +\sum_{j=1}^{13}{\varpi_{j}}_{j} P_{t-j}+\sum_{j=1}^{13} \theta_{j} S P_{t-j}+\sum_{j=1}^{13} \psi_{j} B C I_{t-j}+\mu_{2, t}
\end{aligned}
$$

where $N O I P O_{t}$ represents the percentage of unseasoned issues in each month; $V W U P_{t}$ is a value-weighted underpricing measure; is the number of IPOs in each month; $T P_{t}$ is the term premium in percentage terms; $S P_{t}$ is the monthly percentage change in the $\mathrm{S} \& \mathrm{P} 500$ index; $B C I_{t}$ is the monthly percentage change in the business cycle leading indicator; $\mu_{1, t}$ and $\mu_{2, t}$ are the error terms. Individual parameter values are not reported. $T$-statistics and Wald-tests are corrected for heteroskedascity using White's correction. The $R$-square, $F$-statistic and Wald tests of parameter restrictions are reported for the 13 lags VAR. The Wald tests are tests of variable exclusion. The superscripts $*$ denotes significance at $5 \%$ and $* *$ denotes significance at $10 \%$.

Wald tests tend to highlight the statistical importance of these groups of variables. The first-order lag coefficient for underpricing $(V W U P)$ is .34 and for IPO volume (NOIPO) the first-order lag coefficient is .48, with 
both values statistically significant. ${ }^{16}$ The Wald test for the significance of lagged NOIPO and VWUP in their own regressions supports the autocorrelation features of underpricing and IPO volume. Significant coefficients are observed out to 13 lags for NOIPO and 12 lags for $V W U P$, although not every lag is significant. Hence, time-series persistence is evident in both the variables.

The Wald test indicates that the coefficients on lagged values of $V W U P$ are statistically significant in the NOIPO regression. This is consistent with the correlation results reported in table 6 , that is, underpricing leads $I P O$ volume. Reasons for this relationship, discussed earlier, support the argument that the decision to issue is a function of current observed underpricing. Also consistent with table 6, there is no statistical significance attached to the lagged $N O I P O$ variables included in the $V W U P$ regression. Hence, there is no lead from IPO volume to underpricing.

The economic indicator variables are now considered. Both the lagged term premium $(T P)$ and the lagged market returns as measured by returns on the S\&P500 index (SP) exhibit explanatory power over IPO volume (NOIPO), with statistically significant Wald test statistics. Both variables exhibit significant positive lag coefficient estimates. This is consistent with the findings of Loughran et al. (1994) who suggest a link between equity market performance and the market for IPOs and Choe et al. (1993) who argue that business conditions will impact on IPO activity, although the Wald test for lags of the business cycle variable is not significant. In summary, there is evidence that market conditions lead IPO volume, which is again consistent with an expectation of increased proceeds from the issue leading to a higher frequency of new issues. Of note, the $R^{2}$ (adjusted $R^{2}$ ) is relatively high, indicating the strength of the explanatory variables.

In relation to underpricing, only the lags on the S\&P500 returns are significant in the Wald test, and the significant lags are again positive in sign. This result is perhaps unsurprising given that underpricing itself is inevitably driven in part by the stock market return, and it suggests that

16. These coefficient estimates are somewhat smaller than the respective figures of .66 and .89 reported by Ibbotson et al. (1994) though they are both statistically significant. The more extensive model specification used in this paper may explain the difference in magnitude between these coefficient estimates and those of Ibbotson et al. (1994). 
current stock market conditions help predict the degree of future underpricing. ${ }^{17}$ This finding is consistent with the hypothesis that underwriters observe current market conditions and see windows of opportunity. They convince new issuers to go public and at the same time underprice the issues to provide benefits of underpricing to valued clients. That is, strong continuing market conditions allow the issuer, underwriter and investors to benefit from improved valuations.

\section{Conclusion}

This paper analyzes the behavior of the US IPO market to formally document the existence of hot and cold issue periods and to examine different characteristics of the market, focussing on the volume and underpricing of new issues.

The application of a Markov regime-switching model documents a number of regime switches between hot and cold issue markets over the period 1976 to 1998 . Hot periods are characterized by high volume and large underpricing measures. The results generally confirm previous 'speculative' evidence of hot issue periods. Nevertheless, the objective dating of hot periods is a contribution itself. The paper then documents a leading relationship between underpricing and IPO volume of up to six months. This relationship supports the contention that the decision to issue is a function of current underpricing. The paper hypothesises that current underpricing contains value relevant information, and that issuers and/or underwriters take advantage of this information. Support for this argument is provided by a VAR analysis which reveals that lags of stock market conditions and business conditions contain significant explanatory power over the number of new issues. However, timing the market comes at a risk, as the IPO volume measures are relatively slow to respond to downturns in the market. In relation to underpricing itself, the paper documents a strong autocorrelation in the underpricing series and

17. Results of the time series model suggest the possibility that it could be used to forecast IPO market conditions. While the explanatory power of the model appears quite strong, analysis of its out-of-sample predictive ability is beyond the scope of this paper but is left for future research. 
a significant relationship between underpricing and lags of stock market returns. This latter result suggests that current stock market conditions provide some predictive power over the degree of future underpricing which is valuable information to issuers, underwriters and investors. Overall, the results yield new insights into the IPO market that pave the way for a richer understanding of this important and intriguing area.

\section{References}

Allen, F., and Faulhaber, G. R. 1989. Signaling by underpricing in the IPO market. Journal of Financial Economics 23:303-323.

Chen, N.F.; Roll. R.; and Ross, S. A. 1986. Economic forces and the stock market. Journal of Business 56:383-403.

Choe, H.; Masulis, R. W.; and Nanda, V. 1993. Common stock offerings across the business cycle: Theory and evidence. Journal of Empirical Finance 3:3-31.

Edwards, F.R., and Zhang, X. 1998. Mutual funds and stock and bond market stability. Journal of Financial Services Research 13:257-282.

Firth, M. 1997. An analysis of the stock market performance of new issues in New Zealand. Pacific Basin Finance Journal 5:63-85.

Gray, S.F. 1996. Modeling the conditional distribution of interest rates as regime-switching process. Journal of Financial Economics 42:27-62.

Greene, W. H. 1993. Econometric analysis $2^{\text {nd }}$ edition. New York: Macmillan.

Gujarati, D. M. 1995. Basic Econometrics $3^{\text {rd }}$ edition. New York: McGraw-Hill Inc.

Hamilton, J. D. 1989. A new approach to the economic analysis of nonstationary time series and the business cycle. Econometrica 57:357-384.

Hamilton, J.D., and Lin, G. 1996. Stock market volatility and the business cycle. Journal of Applied Econometrics 11:573-593.

Harvey, C. R. 1988. The real term structure and consumption growth. Journal of Financial Economics 22:305-333.

Helwege, J., and Liang, N. 1996. Initial public offerings in hot and cold markets. Working paper. New York: Federal Reserve Bank of New York.

Ibbotson, R. G., and Jaffe, J. F. 1975. Hot issue markets. Journal of Finance 30:1027-1042.

Ibbotson, R. G.; Sindelar, J. L.; and Ritter, J. R. 1988. Initial public offerings. Journal of Applied Corporate Finance 1:37-45. 
Ibbotson, R. G.; Sindelar, J. L.; and Ritter, J. R. 1994. The market's problems with the pricing of initial public offerings. Journal of Applied Corporate Finance 7:66-74.

Ibbotson, R.G., and Ritter, J. R. 1995. Initial public offerings. In R. A. Jarrow, V. Maksimovic, and W. T. Ziemba. Handbooks in Operations Research and Management Science: Volume 9 Finance North-Holland: Elsevier Science.

Jain, B. A. 1994. The underpricing of 'unit' initial public offerings. Quarterly Review of Economics and Finance 4:309-325.

Jain, B. A. 1995. The relationship between pricing of dealership services and the underpricing of initial public offerings. American Business Review 22-29.

James, K., and Kieschnick, R. 1997. An analysis of fluctuations in the US IPO market. Working Paper. New York: Securities and Exchange Commission of USA.

Keim, D.B., and Stambaugh, R. F. 1986. Predicting returns in the bond and stock markets. Journal of Financial Economics 17:357-390.

Jones, C. P. 1996. Investments: Analysis and Management $5^{\text {th }}$ edition. New York: John Wiley \& Sons.

Layton, A. P. 1996. Dating and predicting phase changes in the US business cycle. International Journal of Forecasting 12:417-428.

Lipman, F. D. 1997. Going Public, New York: Prima Publishing.

Loughran, T., and Ritter, J. R. 1995. The new issues puzzle, Journal of Finance 50:23-51.

Loughran, T., and Ritter, J. R. 2000. Why don't issuers get upset about leaving money on the table in IPOs. Working paper. Florida: University of Florida.

Loughran, T.; Ritter, J. R.; and Rydqvist, K. 1994. Initial public offerings: International insights, Pacific-Basin Finance Journal 2:165-199.

Montgomery, D. C. 1991. Introduction to Statistical Quality Control New York: John Wiley \& Sons.

Myers, S., and Majluf, N. 1984. Corporate financing and investment decisions when firms have information that investors do not have. Journal of Financial Economics 13:187-221.

Neal, R., and Wheatley, S. M. 1998. Do measures of investor sentiment predict returns. Journal of Financial and Quantitative Analysis 33:523-547.

Nelling, E. F.; Mahoney, J. M.; Hildebrand, T. L.; and Goldstein, M. A. 1995. Real estate investment trusts, small stocks and bid-ask spreads. Real Estate Economics 22:45-64.

Peavy, J. W. 1990. Returns on initial public offerings of closed-end funds, Review of Financial Studies 3:695-709. 
Rajan, R., and Servaes, H. 1993. The effect of market conditions on initial public offerings. Working paper. Chicago: University of Chicago.

Rajan, R., and Servaes, H. 1997. Analyst following of initial public offerings. Journal of Finance 52:507-529.

Rees, W. P. 1997. The arrival rate of initial public offerings in the UK. European Financial Management 3:45-62.

Ritter, J. R. 1984. The 'hot issue' market of 1980. Journal of Business 57:215-240.

Ritter, J. R. 1991. The long run performance of initial public offerings, Journal of Finance 46:3-28.

Ritter, J. R. 1998. Initial Public Offerings. In W. Gorham and Lamont, Handbook of Modern Finance.

Rock, K. 1986. Why new issues are underpriced, Journal of Financial Economics 15:187-212.

Schaller, H., and van Nordon, S. 1997. Regime switching in stock market returns. Applied Financial Economics 7:177-191.

Schultz, P. 1993. Unit initial public offerings: A form of staged financing. Journal of Financial Economics 34:199-229.

Sirmans, C. W., and Sirmans, C. F. 1987. The historical perspective of real estate returns. Journal of Portfolio Management 13:22-31.

Wang, K.; Chan, S. H.; and Gau, G. W. 1992. Initial public offerings of equity securities: Anomalous evidence using REITs. Journal of Financial Economics 31:381-410. 